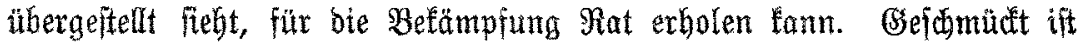

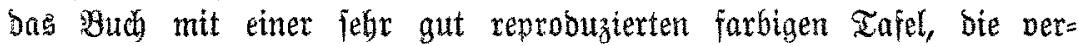

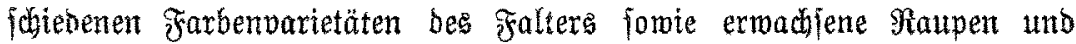
ein eierlegendes $23 e i b d e n$ baritellend, das leiber in falicher Stellung wiebergegeben ift (es fitht in $\mathfrak{B i r f l i d t e t t}$ bei ber Eiablage an ber Rabel

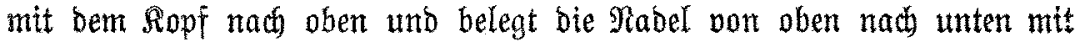
ber \&egeröhre um bie Mabel greifend). Gerner find nod weitere idwarze Tafeln betgegeben, faft burdjwegs Aufnabmen des $\mathfrak{B}$ erfaffers, welche die

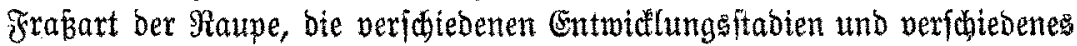
anbere wiebergeben.

Suctoter.

\title{
IV. alutîzen.
}

\section{Prüfung für den Revierverwaltungsoienft der Privaten.}

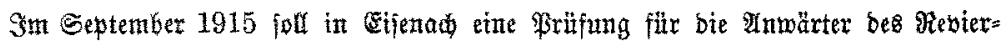
verwaltungsbienftes ber Brivaten abgehalten werben, joferne fid minbeften 6 Ranbibaten

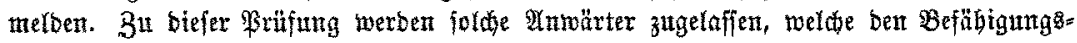

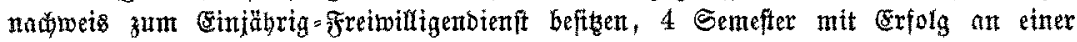

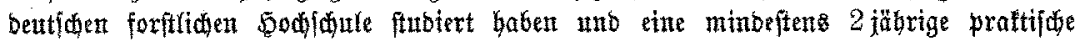

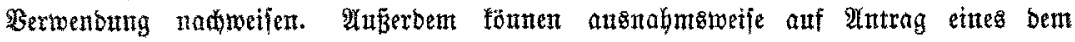

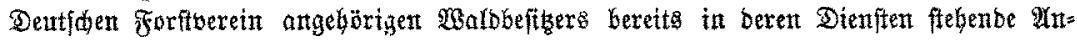

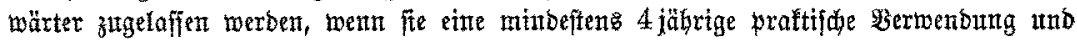
eine genitgente allgemeine Biloung nadpeifen.

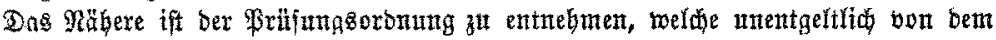
Sbmarn bes Prufungsan

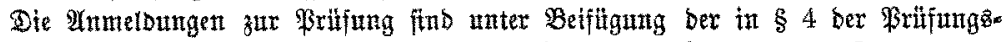

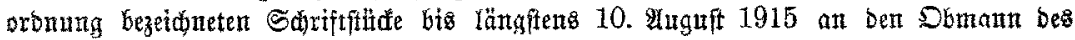

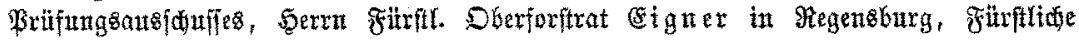
Domänentammer, etrzalentent.

\section{forftlidie Dorlejungen.}

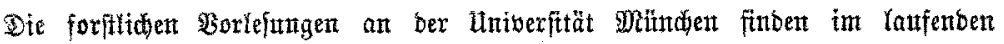
Semefter vor einer fleinen Babl bon Sörern ftatt. Site Borfefung itber Malbban fär

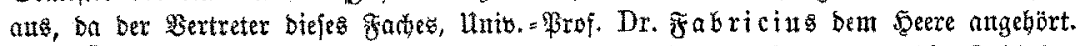

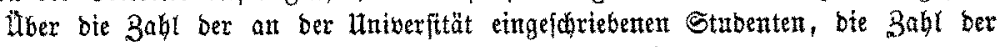
ariegsteilnebmer nerben wix bemübift an biefer Stefle beriøten.

\section{Todesmađricht.}

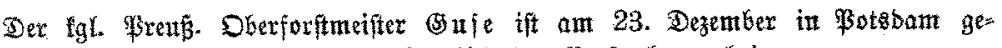

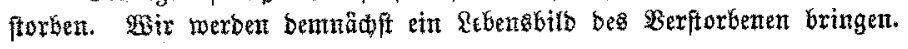

